
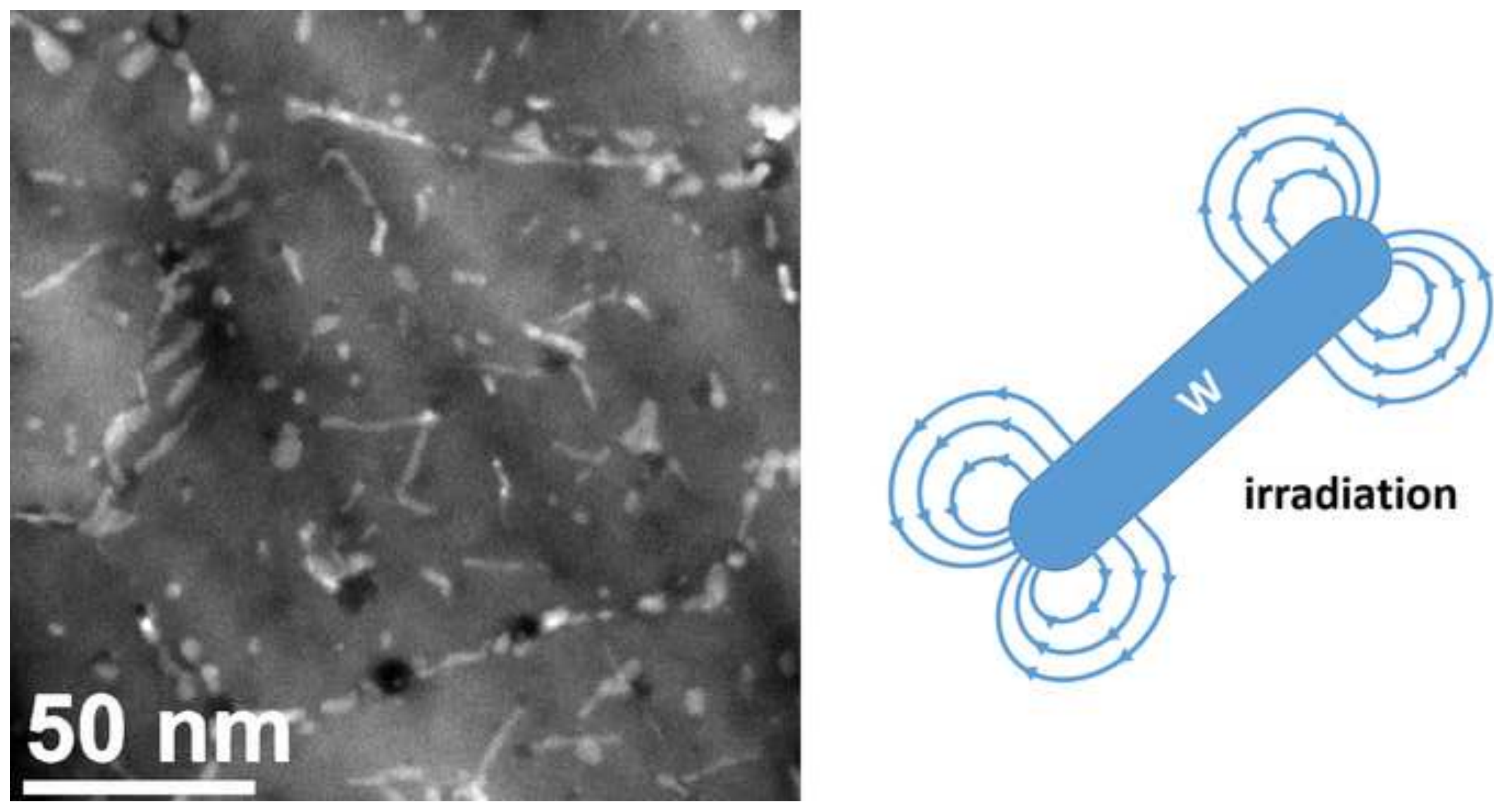


\title{
Irradiation-induced formation of nanorod
}

\section{precipitates in a dilute $\mathrm{Cu}-\mathrm{W}$ alloy}

\author{
Shipeng Shu ${ }^{*}, 1$, Xuan Zhang ${ }^{2}$, John Beach, Pascal Bellon, Robert S. Averback \\ Department of Materials Science and Engineering, University of Illinois at Urbana-Champaign, \\ Urbana, Illinois 61801, USA
}

\footnotetext{
* Corresponding author. E-mail address: shu13@illinois.edu (Shipeng Shu).

${ }^{1}$ Currently at Department of Materials Science and Engineering, University of Wisconsin Madison, Madison, Wisconsin 53706, USA.

${ }^{2}$ Currently at Nuclear Engineering Division, Argonne National Laboratory, Lemont, Illinois 60439, USA.
} 


\begin{abstract}
Radiation-enhanced precipitation of $\mathrm{W}$ has been investigated in dilute $\mathrm{Cu}-\mathrm{W}$ alloys. While spherical W precipitates are stabilized during irradiation below $\sim 300{ }^{\circ} \mathrm{C}$ and above $\sim 600{ }^{\circ} \mathrm{C}$, irradiation at $500^{\circ} \mathrm{C}$ results in the formation of nanorods. Furthermore, use of two-step irradiations, first one at $600{ }^{\circ} \mathrm{C}$ followed by one at $500^{\circ} \mathrm{C}$, indicates that the morphological transformation is reversible. The stabilization of $\mathrm{W}$ nanorods is rationalized using a model introduced by Frost and Russell to explain size stabilization of precipitates formed during irradiation, but extended here to consider precipitate morphology.
\end{abstract}


Keywords: Ion irradiation; Precipitate morphology; Self-organization; Radiation-enhanced diffusion 
The detailed structure of the precipitates in precipitation hardened alloys is well known to have a profound effect on the mechanical and electrical properties of a material. Van Sluytman et al., for example, recently showed that the favorable high-temperature mechanical properties of nickel-based $\gamma-\gamma^{\prime}$ alloys are directly correlated with an optimum precipitate shape [1]. Similarly, the ratio of interfacial area to volume in $\mathrm{Sb}_{2} \mathrm{Te}_{3}$ precipitates have been shown to strongly influence the thermoelectric efficiency of $\mathrm{Sb}_{2} \mathrm{Te}_{3}-\mathrm{PbTe}$ pseudobinary compounds [2]. In turn, the morphology of a precipitate can be determined by many factors, both thermodynamic, including elastic coherency strain and interfacial free energy [3], and kinetic [4]. For the latter, irradiation with energetic particles has long been known to influence precipitation behavior, beyond simply enhancing the nucleation and growth rates. Radiation-induced precipitation $[5,6]$ and dissolution $[7,8]$, compositional patterning $[9,10]$, and ion beam shaping $[11,12]$ are a few examples. In this article, we report on the effect of irradiation conditions on the morphology of the precipitates. Specifically, we show that $\mathrm{W}$ precipitates can grow into rod-like shapes, with aspect ratios as large as $\sim 10$, during irradiation of a $\mathrm{Cu}-1.5$ at. $\% \mathrm{~W}$ alloy at $\sim 500{ }^{\circ} \mathrm{C}$, but not at significantly higher or lower temperatures. We provide evidence, moreover, that the rod-like morphology represents a steady state of the alloy for the chosen irradiation conditions.

The $\mathrm{Cu}_{98.5} \mathrm{~W}_{1.5}$ samples were prepared by physical vapor deposition at room temperature, using DC magnetron sputtering, on oxidized Si wafers. The background pressure in the growth chamber was $\sim 2 \times 10^{-8}$ Torr. Film thicknesses were $\approx 300 \mathrm{~nm}$; details of the growth process can be found elsewhere [13]. A 2-3 nm W capping layer was deposited on the top surface of the film to reduce sputtering during the prolonged irradiations. Cross-section TEM revealed that the capping layer remained largely intact during irradiation. All the samples were first irradiated at room temperature (RT) using $1.8 \mathrm{MeV} \mathrm{Kr}$ ions to a dose of $2.7 \times 10^{16}$ ions $\cdot \mathrm{cm}^{-2}(\sim 60$ 
displacements per atom (dpa)) and then irradiated at elevated temperatures to different doses. The first RT irradiation step is performed to nucleate a high density of W nano-precipitates with diameters $\approx 1-2 \mathrm{~nm}[14,15]$. This pre-irradiation treatment also increases the average grain size from less than $\sim 50 \mathrm{~nm}$ to $\sim 200 \mathrm{~nm}$. The irradiation beam current in these experiments was limited to $\approx 100 \mathrm{nA}$ for $\mathrm{RT}$ irradiation, and $\approx 75 \mathrm{nA}$ for elevated-temperature irradiation, to prevent significant beam heating, $<10{ }^{\circ} \mathrm{C}$. The samples were characterized using scanning transmission electron microscopy (STEM).

Fig. 1 shows high-angle annual dark-field (HAADF) micrographs of a $\mathrm{Cu}_{98.5} \mathrm{~W}_{1.5}$ sample, first irradiated at RT, then irradiated at $500{ }^{\circ} \mathrm{C}$ for two different doses, $2.0 \times 10^{16}$ ions $\cdot \mathrm{cm}^{-2}$ (Fig. 1(a)) and $7.0 \times 10^{16}$ ions $\cdot \mathrm{cm}^{-2}$ (Fig. 1(b)). In both micrographs, the bright regions reveal the $\mathrm{W}$ precipitates. $\mathrm{Cu}$ grain boundaries are decorated by strings of $\mathrm{W}$ precipitates. In the grain interior, surprisingly, many $\mathrm{W}$ precipitates deviate from the equiaxed and nearly spherical shape found after RT irradiation [14, 16, 17], taking an elongated, rod-like shape. We consider a W precipitate to be a "W rod" if its aspect ratio is greater than 3. This criterion ensures that two abutting spherical $\mathrm{W}$ precipitates are not counted as a $\mathrm{W}$ rod. The volume fraction of $\mathrm{W}$ precipitates comprised of $\mathrm{W}$-nanorods in the grain interior is $\approx 9 \%$ in the low-dose sample and $\approx$ $54 \%$ in the high-dose sample. Therefore, as the irradiation dose increases, the $\mathrm{W}$ rods grow at the expense of the spherical $\mathrm{W}$ precipitates. The fraction of $\mathrm{W}$ in solution at this temperature is negligible [16]. At the higher dose level, many of the $\mathrm{W}$ rods have aspect ratios as large as 10 . The average diameter of the spherical $\mathrm{W}$ precipitates increases during these high temperature irradiations to $\approx 2.9 \pm 0.1 \mathrm{~nm}$ for the low-dose sample and to $\approx 3.4 \pm 0.1 \mathrm{~nm}$ for the high-dose sample. Notably, the radius of the minor axis measured near the center of the rods in the highdose sample is smaller, $\approx 1.8 \pm 0.1 \mathrm{~nm}$. At both doses, W-precipitate denuded zones with widths 
on the order of 10-20 $\mathrm{nm}$ are observed near the grain boundaries, suggesting long range (radiation-enhanced) diffusion of $\mathrm{W}$ takes place. The orientation of the $\mathrm{W}$ rods in a given $\mathrm{Cu}$ grain was also examined, but no preferential direction was found. The few black nanofeatures in Fig. 1, adjacent to $\mathrm{W}$ precipitates, are bubbles resulting from $\mathrm{Kr}$ implantation [13]. Most $\mathrm{Kr}$, however, $\sim 85 \%$, was transmitted through the film.

Fig. 2 shows the microstructures of a $\mathrm{Cu}_{98.5} \mathrm{~W}_{1.5}$ samples pre-irradiated at $\mathrm{RT}$ and then irradiated at $300{ }^{\circ} \mathrm{C}$ (Fig. 2(a)) or $600{ }^{\circ} \mathrm{C}$ (Fig. 2(b)), each to a dose of $4.0 \times 10^{16}$ ions $\cdot \mathrm{cm}^{-2}$. Very different from the sample irradiated at $500{ }^{\circ} \mathrm{C}$, these samples do not reveal any obvious nanorods; our criterion for distinguishing nanorods yields an average of less than $2.5 \%$. Also, for the sample irradiated at $600{ }^{\circ} \mathrm{C}$, the equiaxed $\mathrm{W}$ precipitates coarsen as irradiation time increases (micrographs not shown). A significant precipitate denuded zone near the grain boundaries is again observed at $600{ }^{\circ} \mathrm{C}$, but not at $300{ }^{\circ} \mathrm{C}$.

To determine whether the rod-like morphology of $\mathrm{W}$ precipitates at $500{ }^{\circ} \mathrm{C}$ represents a steady state, or just a transient along the pathway to a spherical shape, a multi-step irradiation experiment was performed. After irradiating a RT pre-irradiated sample at $600{ }^{\circ} \mathrm{C}$ to a dose of $2.0 \times 10^{16}$ ions $\cdot \mathrm{cm}^{-2}$, the temperature was lowered and the sample irradiated at $500{ }^{\circ} \mathrm{C}$ to a dose of $4.0 \times 10^{16}$ ions $\cdot \mathrm{cm}^{-2}$. The microstructure of this sample after the $500{ }^{\circ} \mathrm{C}$ irradiation is presented in Fig. 3. We see that $\mathrm{W}$ rods again appear in the grain interiors. The fraction of $\mathrm{W}$ precipitates taking the rod-like shape is $\approx 14 \%$. This experiment thus confirms that the rod-like structures in the sample irradiated at $500{ }^{\circ} \mathrm{C}$, i.e., Fig. 1, are not transient shapes, but rather represent the steady state morphology of the $\mathrm{W}$ precipitates.

In attempting to rationalize the formation of nanorods during irradiation at $500{ }^{\circ} \mathrm{C}$, we first consider whether the morphology of the precipitates is a consequence of either coherency strains 
or interfacial energies. In the case of the $\mathrm{Cu}-\mathrm{W}$ system, however, neither factor seems sufficient to explain our observations. Previous studies, for example, have reported that the 1-2 nm sized W precipitates induced by RT irradiation are not coherent with the $\mathrm{Cu}$ matrix $[13,17]$, arguing against an important role for interface energies. Moreover, the $\mathrm{W}$ rods do not show a preferential orientation in the $\mathrm{Cu}$ matrix, suggesting that neither interface energies nor coherency strains are controlling the shape evolution. The observation that the $\mathrm{W}$ precipitates become equiaxed during $600{ }^{\circ} \mathrm{C}$, moreover, further argues against interfacial and strain effects. We therefore seek an alternative explanation for the formation of the $\mathrm{W}$ nanorods based on kinetic factors; we propose that the $\mathrm{W}$ nanorods form by a self-organization process, similar to that described first by Nelson, Mazey, and Hudson [18], and later refined by Frost and Russell [7].

We recall in the model by Frost and Russell, that self-organization derives from a dynamical competition between ballistic recoil events of length $R$ in energetic displacement cascades and thermally activated (radiation-enhanced) diffusion mediated by point defects. Since the length scales of these two processes are significantly different, one (thermal diffusion) tends to dominate on small length scales (nearest-neighbor distance, $\sim 0.2 \mathrm{~nm}$ ), while the other (ballistic events) tends to dominate at large length scales (distribution of exponential decay with a decay length $\mathrm{R} \sim 0.3 \mathrm{~nm}[19])$. In this way, the system can organize on small length scales (i.e., form precipitates), but disorder on large length scales (i.e., the precipitates do not undergo macroscopic coarsening). The alloy thus selects a characteristic length scale depending on the temperature and irradiation flux. Our picture for the formation of $\mathrm{W}$ nanorods is based on the idea that the characteristic length scale for a nanorod is different along the cylindrical portion of the rod than at the spherical ends of the rod, simply because the curvatures and dimensionality in these two regions are different. We test this idea by comparing the steady-state $\mathrm{W}$ concentration 
in the matrix adjacent to the precipitate near the two ends of the elongated precipitate with the $\mathrm{W}$ concentration near the center, i.e., we determine whether atoms near the two ends of the rod will feed the center, favoring a spherical precipitate, or the atoms near the center part of the rod feed the two ends, leading to steady growth of the rod. In order to avoid considering the complex geometry of a nanorod, we simply consider here two situations: a pure precipitate of fixed radius $r_{p}$, and an infinitely long cylindrical precipitate, with the same radius. Frost and Russell have analytically solved the problem for the spherical geometry, using a simplified description of recoil mixing with a single relocation distance. The steady-state concentration profile can then be found by solving the Poisson equation

$$
\frac{\partial c}{\partial t}=D_{i r r} \nabla^{2} c+G=0
$$

with the following boundary conditions

1. $c=c_{0}$ at $r=r_{p}$

2. $(\partial c / \partial r)=0$ at $r=L / 2$, where $L$ is the interspacing between the centers of two spheres/cylinders.

In Eq. (1), $D_{i r r}$ is the radiation enhanced diffusion coefficient of the solute. The source term $G(r)$ is the rate of solute deposition into the matrix by recoil mixing. For the spherical geometry, Frost and Russell [7] derived an analytical expression for $G(r)$. For the cylindrical geometry of interest here, however, the source term cannot be obtained analytically, even with the approximation of single ballistic relocation distance $R$. We thus calculate the source term numerically, using a binary collision model code developed by Schwen et al. [20]. The source terms for both the spherical and cylindrical geometries are shown in Fig. 4(a). Then, solving Eq. (1) at $500{ }^{\circ} \mathrm{C}$ numerically for both the spherical and cylindrical geometries yields the solutions shown in Fig. 4(b), using rate equations and assuming the sink-elimination regime for point 
defect annihilation for the calculation of $D_{i r r}$ [21]. For the cylindrical geometry, the steady-state far-field concentration of $\mathrm{W}$ is higher than that of the spherical geometry, and consequently we expect the $\mathrm{W}$ atoms to flow from the center of the rod towards the two ends, leading to the onedimensional growth of the rod. Further analysis shows that this effect is due to the geometryspecific source term, rather than the geometry of the diffusion problem. Indeed the higher $\mathrm{W}$ farfield concentration for cylinders persists even in the (unphysical) case where the two distinct source terms are employed in Eq. (1) but with the same diffusion geometry, i.e., around a sphere or around a cylinder. While our calculation is very much simplified, it gains support from the experimental observation that the minor axes of the $\mathrm{W}$ rods are generally smaller than the diameters of the spherical W precipitates, see Fig. 1. Rods are not expected to form below 300 ${ }^{\circ} \mathrm{C}$, since thermally activated (radiation-enhanced) diffusion becomes too small, relative to ballistic mixing for this self-organization process to occur, while above $\sim 600{ }^{\circ} \mathrm{C}$, thermally diffusion of $\mathrm{W}$ in $\mathrm{Cu}$ becomes significant [15], and interfacial diffusion of $\mathrm{W}$ at the precipitate/matrix interface will spheroidize the precipitates. While the Frost-Russell model thus seemingly rationalizes our experimental observation, a more detailed calculation of the stability of the nanorods will be necessary before a definitive conclusion can be drawn concerning how the nanorod formation takes place. We believe, however, that the formation of nanorods requires a very low self-diffusion coefficient of the solute species relative to the matrix to prevent spheroidization by interface diffusion, and therefore limited to systems similar to $\mathrm{Cu}-\mathrm{W}$, e.g., $\mathrm{Cu}-\mathrm{Ta}$ and $\mathrm{Ag}-\mathrm{Ni}$. Finally, we note that irradiation of $\mathrm{SiO}_{2}$ by swift heavy ions was recently reported to transform spherical $\mathrm{Au}$ and other metal nanoprecipitates into rods [11, 12], but this observation involves electronic excitation and inhomogeneous deformation, which are not 
relevant here. This morphological transformation in $\mathrm{SiO}_{2}$, moreover, is irreversible, contrary to our findings for $\mathrm{Cu}-\mathrm{W}$.

The authors thank Daniel Schwen and Zebo Li for valuable discussions. This research was supported by US National Science Foundation under Grant Number DMR-1306475. The work was carried out in part in the Frederick-Seitz Materials Research Laboratory Central Facilities, University of Illinois at Urbana-Champaign.

References

[1] J.S. Van Sluytman, T.M. Pollock, Acta Mater., 60 (2012) 1771-1783.

[2] Y. Liu, L. Chen, J. Li, Acta Mater., 65 (2014) 308-315.

[3] V. Vaithyanathan, C. Wolverton, L.Q. Chen, Physical Review Letters, 88 (2002) 125503.

[4] Z. Mao, C.K. Sudbrack, K.E. Yoon, G. Martin, D.N. Seidman, Nat Mater, 6 (2007) 210-216.

[5] R. Cauvin, G. Martin, Phys. Rev. B, 23 (1981) 3322-3332.

[6] R. Cauvin, G. Martin, Phys. Rev. B, 23 (1981) 3333-3348.

[7] H.J. Frost, K.C. Russell, Acta Metallurgica, 30 (1982) 953-960.

[8] H.J. Frost, K.C. Russell, J. Nucl. Mater., 104 (1981) 1427-1432.

[9] R.A. Enrique, P. Bellon, Physical Review Letters, 84 (2000) 2885-2888.

[10] S.W. Chee, B. Stumphy, N.Q. Vo, R.S. Averback, P. Bellon, Acta Mater., 58 (2010) 40884099.

[11] E.A. Dawi, G. Rizza, M.P. Mink, A.M. Vredenberg, F.H.P.M. Habraken, J. Appl. Phys., 105 (2009) 074305. 
[12] M.C. Ridgway, R. Giulian, D.J. Sprouster, P. Kluth, L.L. Araujo, D.J. Llewellyn, A.P. Byrne, F. Kremer, P.F.P. Fichtner, G. Rizza, H. Amekura, M. Toulemonde, Physical Review Letters, 106 (2011) 095505.

[13] X. Zhang, S. Shu, P. Bellon, R.S. Averback, Acta Mater., 97 (2015) 348-356.

[14] S. Shu, X. Zhang, P. Bellon, R.S. Averback, Materials Research Letters, (2015) 1-5.

[15] N.Q. Vo, S.W. Chee, D. Schwen, X. Zhang, P. Bellon, R.S. Averback, Scr. Mater., 63 (2010) 929-932.

[16] X. Zhang, J. Beach, R.S. Averback, P. Bellon, in, (unpublished).

[17] X. Zhang, J.G. Wen, P. Bellon, R.S. Averback, Acta Mater., 61 (2013) 2004-2015.

[18] R.S. Nelson, D.J. Mazey, J.A. Hudson, J. Nucl. Mater., 44 (1972) 318-330.

[19] R.A. Enrique, K. Nordlund, R.S. Averback, P. Bellon, J. Appl. Phys., 93 (2003) 2917-2923.

[20] D. Schwen, M. Huang, P. Bellon, R.S. Averback, J. Nucl. Mater., 392 (2009) 35-39.

[21] S. Shu, P. Bellon, R.S. Averback, Phys. Rev. B, 91 (2015) 214107. 
Figure 1. High-angle annual dark-field (HAADF) STEM micrographs showing microstructural evolution of the pre-irradiated $\mathrm{Cu}_{98.5} \mathrm{~W}_{1.5}$ sample irradiated at $500{ }^{\circ} \mathrm{C}$ to a dose of (a) $2.0 \times 10^{16}$ ions $\cdot \mathrm{cm}^{-2}$ (b) $7.0 \times 10^{16}$ ions $\cdot \mathrm{cm}^{-2}$.

Figure 2. HAADF STEM micrographs showing microstructural evolution of the pre-irradiated $\mathrm{Cu}_{98.5} \mathrm{~W}_{1.5}$ sample irradiated at (a) $300{ }^{\circ} \mathrm{C}$ and (b) $600{ }^{\circ} \mathrm{C}$ to a dose of $4.0 \times 10^{16}$ ions $\cdot \mathrm{cm}^{-2}$.

Figure 3. HAADF STEM micrographs showing microstructural evolution of the pre-irradiated $\mathrm{Cu}_{98.5} \mathrm{~W}_{1.5}$ sample irradiated at $600{ }^{\circ} \mathrm{C}$ to a dose of $2.0 \times 10^{16}$ ions $\cdot \mathrm{cm}^{-2}$ then at $500{ }^{\circ} \mathrm{C}$ for another dose of $4.0 \times 10^{16}$ ions $\cdot \mathrm{cm}^{-2}$.

Figure 4. (a) Numerically calculated source term G(r) for spherical and cylindrical geometry (top two rows), scaled by the dpa rate (dpa/s); bottom row shows the difference between the source terms for cylindrical and spherical geometries; $r$ is the radius of the sphere or the radius of the cylinder for the two geometries (b) W atomic concentration profile obtained by solving the Poisson equation. Inset is a schematic showing the flow of material around an elongated precipitate in the rod-forming condition. (For interpretation of the references to color in this figure legend, the reader is referred to the web version of this article.) 

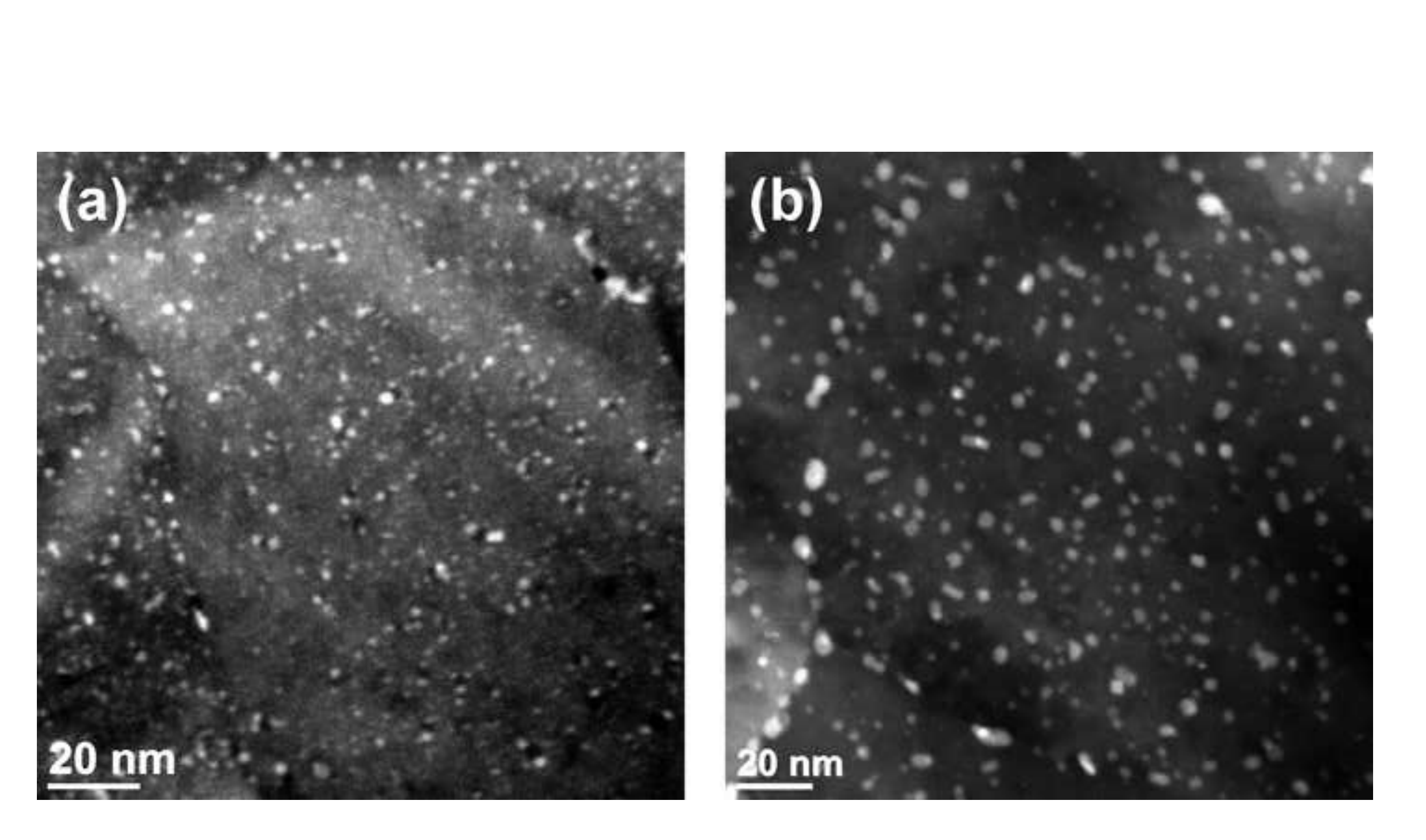

\section{(s)}
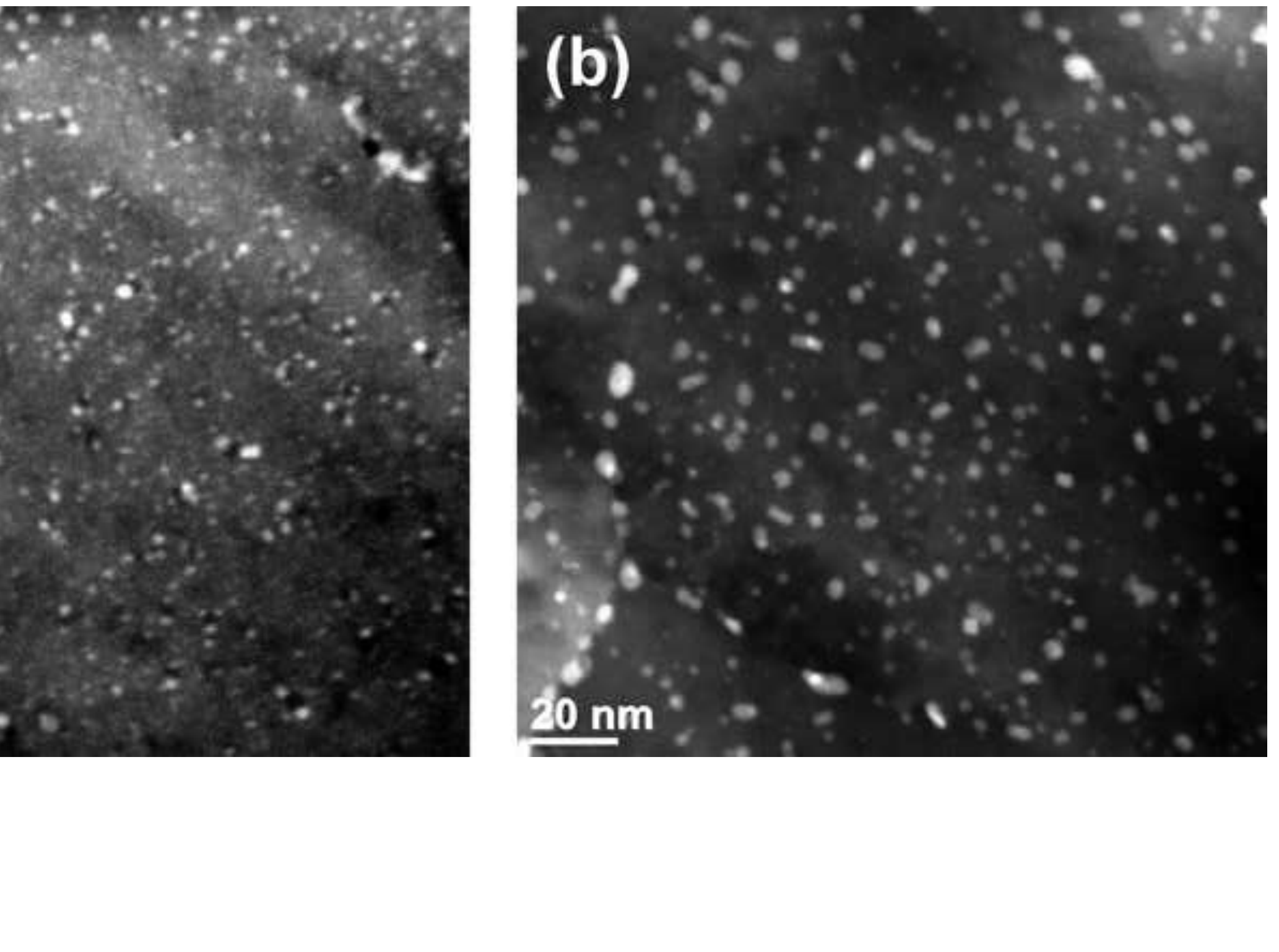


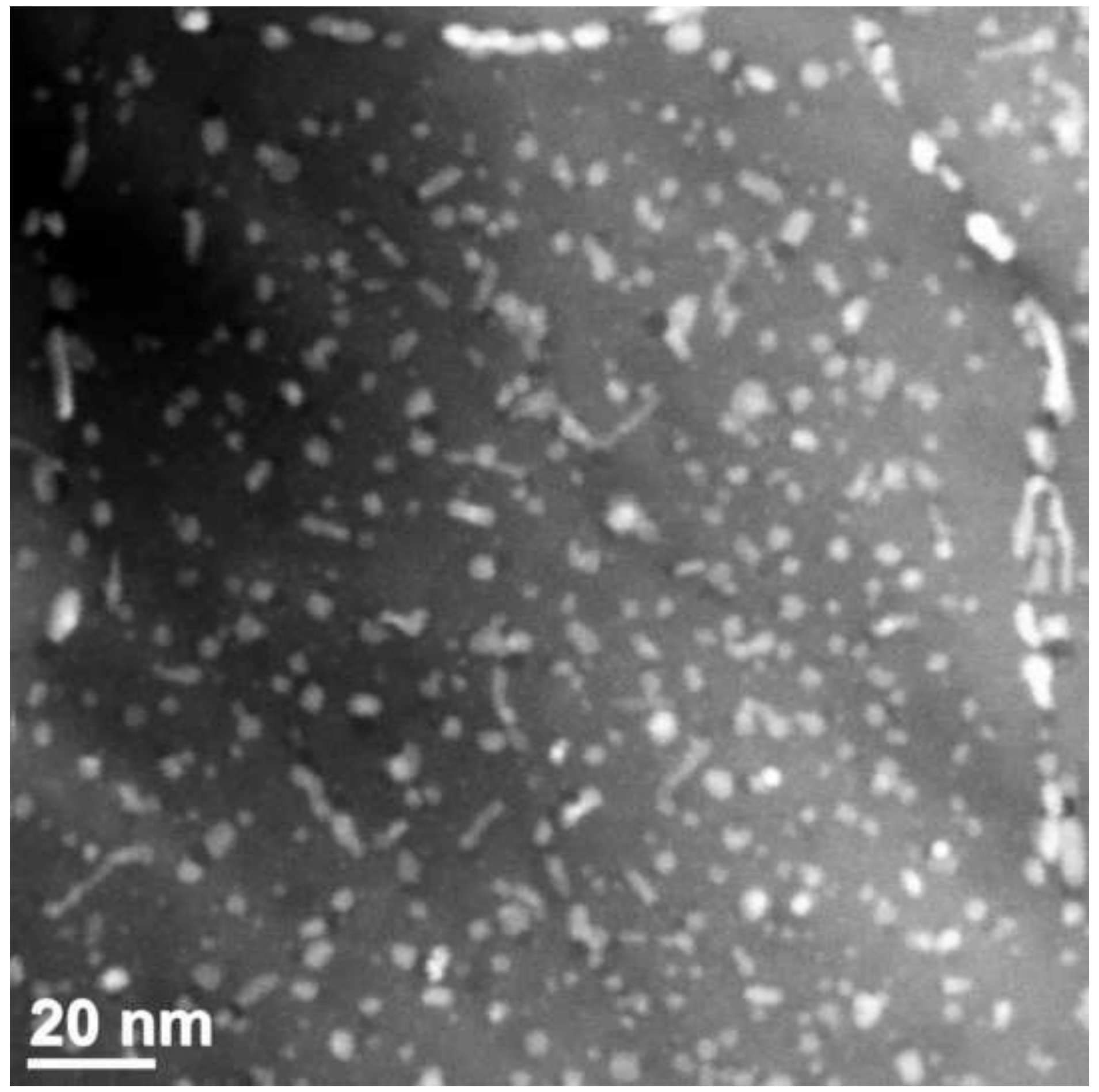


(a)

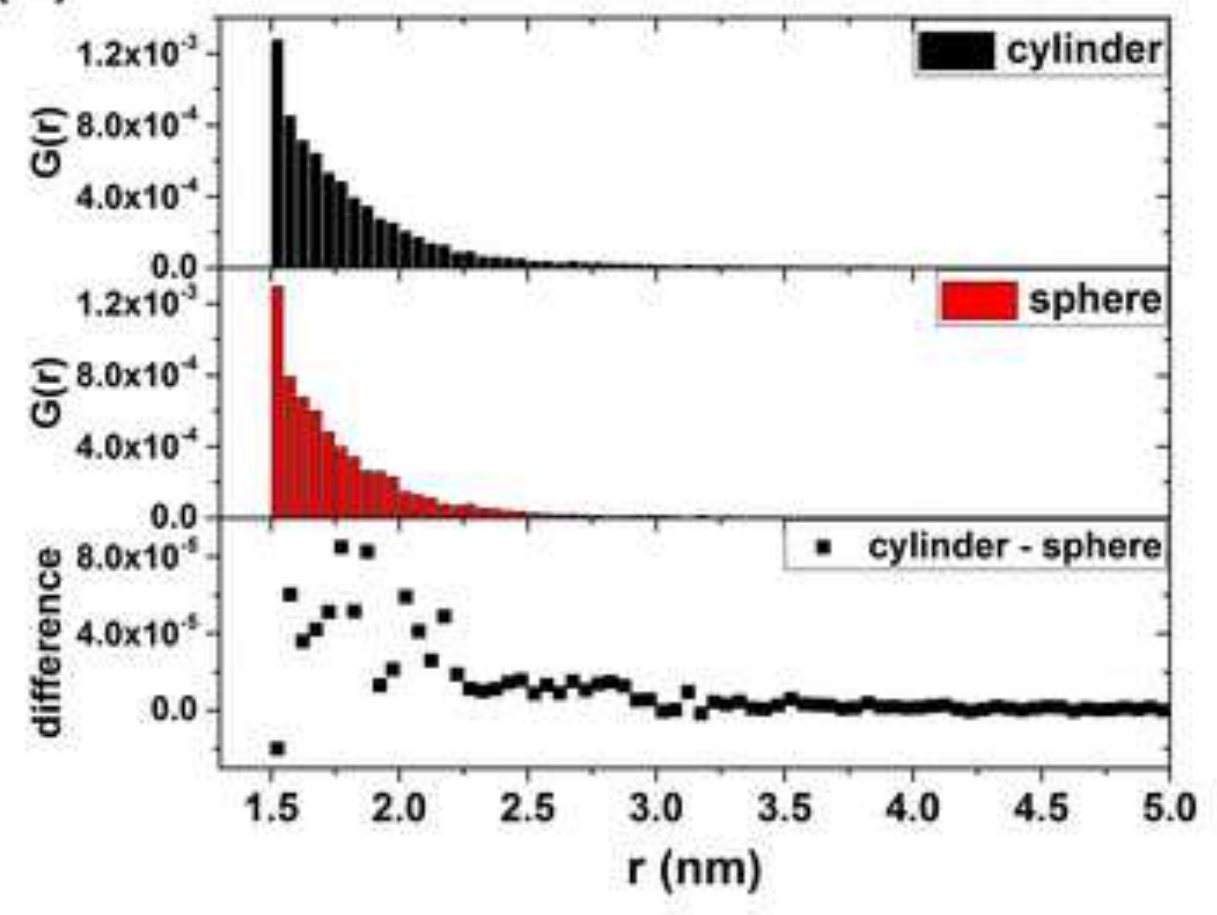

(b)

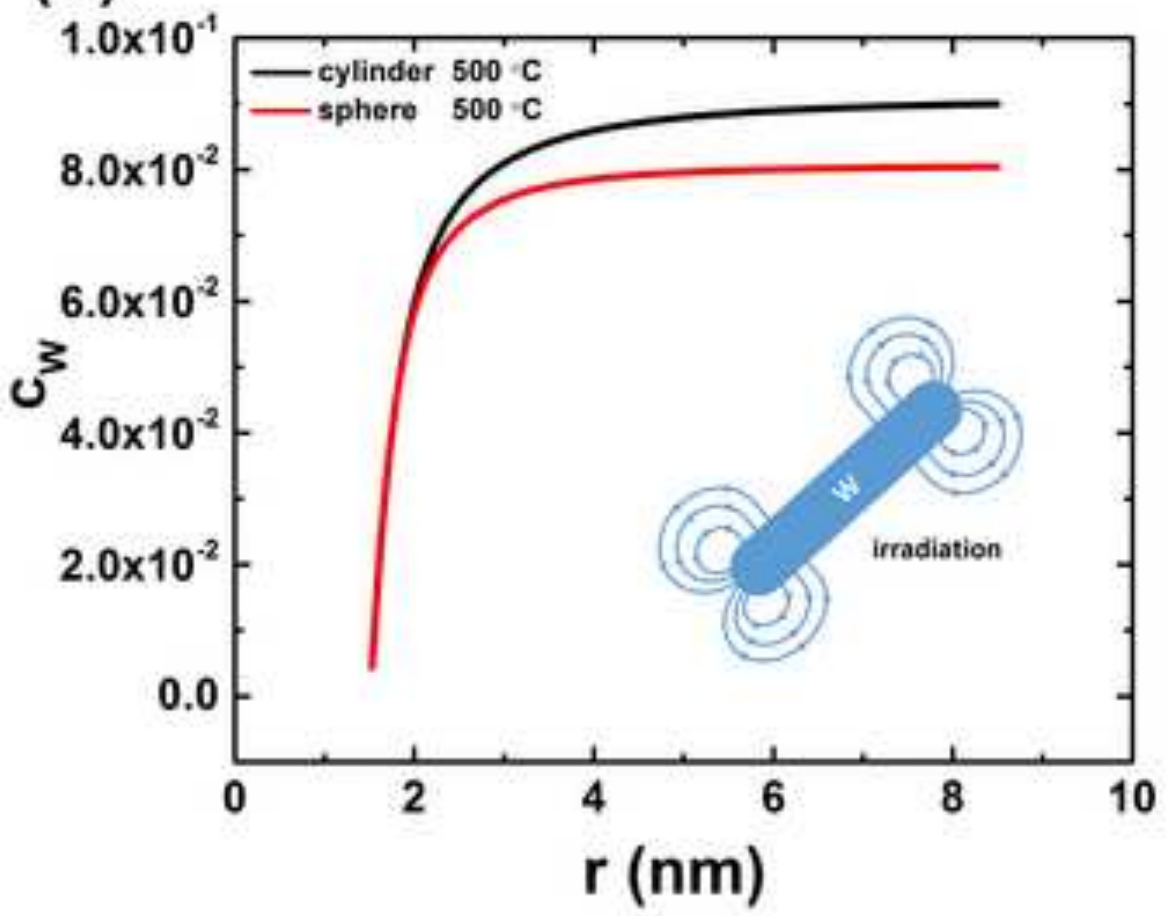

